\section{Nutrition During Critical Care: An Audit on Actual Energy and Protein Intakes}

\author{
Loïc Rougier, $\mathrm{MD}^{\mathbf{1}}$; Jean-Charles Preiser, $\mathrm{PhD}^{2}$ (D); Marjorie Fadeur, $\mathbf{R D}^{3}$; \\ Anne-Marie Verbrugge, $\mathrm{RD}^{3}$; Nicolas Paquot, $\mathrm{PhD}^{3,4}$; Didier Ledoux, $\mathrm{PhD}^{3,5}$; \\ Benoit Misset, $\mathrm{MD}^{5}$; and Anne-Françoise Rousseau, $\mathbf{P h D}^{3,5}$ (i)
}

Nutrition

Volume 0 Number 0

xxxx $20201-10$

(C) 2020 American Society for

Parenteral and Enteral Nutrition

DOI: 10.1002/jpen.1962

wileyonlinelibrary.com

WILEY

\begin{abstract}
Introduction: Oral nutrition is delivered frequently in intensive care units (ICUs) but rarely studied. The primary objective of this study was to quantify nutrition intakes in patients exclusively orally fed (OF) and in those receiving medical nutrition solutions or both. Methods: Adults who stayed in a mixed ICU for $\geq 3$ days were studied. Nutrition deficits were calculated as the difference between estimated energy or protein targets (determined by weight-based formulas) and actual intakes (recorded on a daily basis by nurses). Total volumes of enteral or parenteral nutrition solutions, propofol, and glucose infused over 24 hours were collected and energy and protein amounts were calculated. In OF patients, food intake at each meal (breakfast, lunch, and dinner) was estimated using the "one-quarter portion" method. Results: Among the 289 included patients aged 67 (57-75.5) years, 253 were fed and received, on average, $14.3(7.8-19) \mathrm{kcal} / \mathrm{kg} / \mathrm{d}$ and $0.53(0.27-0.8) \mathrm{g} / \mathrm{kg} / \mathrm{d}$ protein. In OF patients $(\mathrm{n}=126)$, intakes were 9.7 $(5.8-19) \mathrm{kcal} / \mathrm{kg} / \mathrm{d}$ and $0.35(0.17-0.57) \mathrm{g} / \mathrm{kg} / \mathrm{d}$ protein. In the subset of OF patients with ICU stay $\geq 7$ days $(\mathrm{n}=37)$, respectively, $51 \%$ and $94 \%$ never received $\geq 80 \%$ of their energy and protein targets. Conclusion: Nutrition intakes were lower by oral feeding compared with other exclusive or combined medical nutrition. Compared with the prescribed amounts, the deficit was larger for proteins than for energy. (JPEN J Parenter Enteral Nutr. 2020;0:1-10)
\end{abstract}

\title{
Keywords
}

critical care; nutrition; oral intake; protein deficit; quality improvement

\section{Clinical Relevancy Statement}

Patients capable to sustain volitional oral intakes represent a significant part of the patients admitted to intensive care units. This audit aimed to quantify their nutrition intakes: they were significantly lower when compared with exclusive or combined medical nutrition. Comparing with the prescribed targets, the deficit was larger for proteins than for energy. Such results should help persuade critical care teams to view oral nutrition as a key component of critical care and not only as a comfort care.

\section{Introduction}

Malnutrition acquired during intensive care unit (ICU) stay is associated with poor outcomes, such as a prolonged length of stay (LOS), a higher incidence of complications, and, ultimately, an increased mortality. ${ }^{1-3}$ The available literature on nutrition during critical illness raised awareness of the benefits of medical nutrition. Nowadays, nutrition is considered as a major supportive therapy in critically ill patients. These patients have specific nutrition needs, both quantitatively and qualitatively. Scientific societies recently published updated recommendations on nutrition practices in the $\mathrm{ICU}^{4,5}$ that mainly focused on enteral or parenteral nutrition support.

\footnotetext{
From the ${ }^{1}$ Department of Anaesthesiology, University Hospital, University of Liège, Liège, Belgium; ${ }^{2}$ Department of Intensive Care, Erasme University Hospital, Université Libre de Bruxelles, Brussels, Belgium; ${ }^{3}$ Multidisciplinary Nutrition Team, University Hospital, University of Liège, Liège, Belgium; ${ }^{4}$ Department of Diabetes, Nutrition and Metabolic Diseases, University Hospital, University of Liège, Liège, Belgium; and the ${ }^{5}$ Department of Intensive Care and Burn Centre, University Hospital, University of Liège, Liège, Belgium.

Financial disclosure: None declared.

Conflicts of interest: J.C.P. declares fees for consultancies and lectures from Baxter, Fresenius, Nestlé, and Nutricia. The other authors declare that they have no competing interests.

Received for publication April 21, 2020; accepted for publication July 1,2020

This article originally appeared online on $\operatorname{xxx} 0,2020$.

Corresponding Author:

Anne-Françoise Rousseau, MD, PhD, Department of Intensive Care and Burn Centre, University Hospital, Avenue Hippocrate, 1/B35, B-4000 Liège, Belgium.

Email: afrousseau@chuliege.be
} 
Because of the lack of data on oral nutrition, recommendations on oral diet are rare in published guidelines and too poor to help in daily practice. In a small cohort of mixed medical and surgical critically ill patients, low oral intakes were observed during the week following extubation. ${ }^{6}$ Likewise, oral intakes were found to be low in patients with traumatic brain injury who exclusively received oral nutrition during their entire hospital stay. ${ }^{7}$ In addition, oral feeding is commonly delayed in the case of swallowing disorders, as is the case after prolonged oral intubation. ${ }^{8,9}$ Finally, low energy and protein intakes were observed in the hospital ward in the post-ICU period, when patients most commonly received oral nutrition. ${ }^{10}$

Oral nutrition in ICU patients seems often overlooked because patients are deemed to be less severely ill. However, the number of patients who are concerned is not insignificant: about $40 \%$ of ICU patients are able to sustain volitional oral intakes. ${ }^{11}$ Moreover, muscle loss is one of the consequences of critical illness-related catabolic state, and rebuilding of muscle will require adequate intakes of both energy and proteins. This is particularly true for long stayers, for whom nutrition support and nutrition rehabilitation are of importance. ${ }^{12}$

Given the paucity of data on the nutrition condition of orally fed (OF) patients in the ICU, we performed an observational study aiming to quantify nutrition intakes during the whole ICU stay in patients who received oral feeding only (ie, meals and oral nutrition supplements [ONSs]), medical nutrition solutions (enteral or parenteral solutions), or both. The secondary aim was to observe the functional status of ICU survivors at hospital discharge, in the subset of long-stayer patients.

\section{Materials and Methods}

This study was conducted during 17 nonconsecutive weeks in 2016 and 2017 in the intensive care department of a tertiary hospital after approval by the local institutional review board (national ref: B707201629526; local ref: 2016/201, October 13, 2016). Information about the study was provided to capable patients and displayed in the ICU waiting rooms to inform relatives. In accordance with the legal requirements, no written consent was required, as it was a noninterventional study (audit of current practice).

\section{Population}

All critically ill adults consecutively admitted to the ICU were screened for eligibility. Patients were excluded in the following cases: anticipated ICU stay was $\leq 2$ days, lack of full commitment to care upon admission, former ICU stay during the same hospital stay, and transfer from another ICU.

\section{Context}

Patients were recruited from a 5-unit and 44-bed intensive care department. It is a mixed medical and surgical ICU: $28 \%$ of the patients are admitted after scheduled cardiac surgery or invasive valvular procedures. Age of admitted patients is $\sim 66$ years, and median ICU LOS is $\sim 5$ days.

\section{Local Nutrition Practices}

Intensivists and dieticians jointly managed the nutrition strategy. To ensure that nutrition management was not left to nurses' judgment, there were no routine orders. Oral nutrition was considered the first choice whenever patients had a functioning gastrointestinal tract and effective and safe swallowing, as routinely assessed by nurses using a water swallowing test. ${ }^{13,14}$ Different hospital-made meals could be served, according to a patient's clinical status (ordinary, enriched, disease-specific, or modified texture diet). Disease-specific diets included low-sodium, diabetic, renal, or postoperative (light) diets. Texture-adapted diet was classified according to the International Dysphagia Diet Standardization Initiative (IDDSI). Patients could also receive supplements, such as hospital-made enriched soup or cream, and ONSs, such as Resource 2.0 Fiber (Nestlé Health Science, Brussels, Belgium) or Fresubin 2kcal Fiber Drink (Fresenius Kabi, Schelle, Belgium). For patients who were unable to receive volitional oral intakes or in case of insufficient oral intakes (based on daily records of actual intakes), nasogastric enteral feeding was prescribed by clinicians, in accordance with dietitian recommendation. Enteral nutrition was administered continuously by using a volumetric pump. Gastric residual volume was monitored every 6 hours: in case of volume $\geq 250 \mathrm{~mL}$, feeding rate was reduced and prokinetics (metoclopramide or erythromycin) were considered at the intensivist's discretion. The different industrial enteral solutions were Nutrison Protein Plus, Nutrison Energy Multi Fiber, Nutrison Soja (Nutricia, Brussels, Belgium), Fresubin HP Energy (Fresenius Kabi, Schelle, Belgium), Novasource Gi Advance, and Peptamen AF (Nestlé Health Science, Brussels, Belgium). In case of insufficient or contraindicated enteral nutrition, respectively, supplemental or full parenteral nutrition was initiated by using a ternary mixture (Smofkabiven, Fresenius Kabi, Schelle, Belgium). Parenteral nutrition was administered continuously via a central venous line by using a volumetric pump.

According to the nutrition guidelines that were available at the time of the study, weight-based formulas were used to estimate energy and protein targets (Table 1) ${ }^{4,15-18}$ Optimal intakes were considered as $80 \%-100 \%$ of energy or protein targets. ${ }^{19}$ 
Table 1. Nutrition Calculations.

Body weight considered for nutrition calculations Eutrophic patients:

- $\quad$ Aged $<75$ y: BMI $=$ $18.5-25$

- $\quad$ Aged $\geq 75 \mathrm{y}: \mathrm{BMI}=$ 23-28

Underweight patients

Actual weight: measured in hospital or obtained from patient's recent medical history

IBW $=$ expected weight for

- $\quad \mathrm{BMI}=18.5$ if aged $<75 \mathrm{y}$

- $\mathrm{BMI}=23$ if aged $\geq 75 \mathrm{y}$

Overweight patients

$\mathrm{IBW}=$ expected weight for

- $\quad \mathrm{BMI}=25$ if aged $<75 \mathrm{y}$

- $\quad \mathrm{BMI}=28$ if aged $\geq 75 \mathrm{y}$

Obese patients:

Adjusted IBW = $\mathrm{IBW}+0.25 \times$ (actual

- $\quad$ Aged $<75$ y: BMI $\geq 30$

- Aged $\geq 75 \mathrm{y}: \mathrm{BMI} \geq 30$ weight-IBW)

Nutrition targets

Eutrophic, underweight, and Energy: $25 \mathrm{kcal} / \mathrm{kg} / \mathrm{d}$ overweight patients

Protein: $1.2 \mathrm{~g} / \mathrm{kg} / \mathrm{d}(1.7 \mathrm{~g} / \mathrm{kg} / \mathrm{d}$ if $\mathrm{CVVH}$ )

Obese patients

Energy: $20 \mathrm{kcal} / \mathrm{kg} / \mathrm{d}$

Protein: $2 \mathrm{~g} / \mathrm{kg} / \mathrm{d}$

BMI was calculated as weight in kilograms divided by height in meters squared.

BMI, body mass index; CVVH, continuous venovenous hemofiltration; IBW, ideal body weight.

\section{Variables and Analyses}

Demographic data (age, sex, weight, height, body mass index [BMI], diagnosis category and main failing organ system, severity scores, organ support duration, weight changes, LOS, and survival) were collected for all patients, from the electronic medical record. The NUTRIC score (based on 5 variables) was calculated according to published formula. ${ }^{20}$ The route of feeding was recorded daily.

Nutrition intakes were recorded from ICU admission to ICU discharge. Total volumes of enteral or parenteral nutrition solutions, propofol. and glucose infused over 24 hours were collected, and energy and protein amounts were calculated. In OF patients, food intake at each meal (breakfast, lunch, and dinner) was estimated by using the one-quarter portion method; intakes were estimated by nurses, using a 5 -point visual scale $\left(0, \frac{1}{4}, \frac{1}{2}, \frac{3}{4}\right.$, all). ${ }^{21}$ Documentation of oral intakes by nursing staff using this method is a routine part of clinical practice at this site. Using the Belgian Food Composition Database (6th Edition, 2017, http://www.nubel.com/fr/table-decomposition-des-aliments.html), the dieticians then converted food intakes into energy and protein amounts according to food composition. Ingested volumes of oral supplements were also recorded and converted. To obtain the total daily energy and protein intakes, the amounts of energy and protein from all sources were added over the 24 hours for each patient. Because of a great variability in admission and discharge hours, energy and protein intakes of the first and last days of ICU stay were not taken into account for cumulative quantification. The difference between actual intakes and prescribed amounts of energy and protein was considered as the primary outcome; a negative difference was considered as a deficit in either energy or protein. Intakes were compared between obese and nonobese patients and between patients with NUTRIC scores $<5$ and $\geq 5$.

Patients were separated into 3 groups according to the type of nutrition provided. The OF group included patients who received only an oral diet (meals and/or ONSs) during the ICU stay. Patients who received both or successively enteral and/or parenteral nutrition and oral nutrition were assigned to the oral + enteral/parenteral (OEP) group. Patients who were exclusively fed with enteral and/or parenteral nutrition were included in the enteral/parenteral nutrition (EPN) group.

Within each group, we separately analyzed energy and protein intakes in the subset of patients with an ICU LOS $\geq 7$ days, whose outcomes are presumably more influenced by nutrition intakes compared with those of short stayers. Moreover, in OF patients with an ICU LOS $\geq 7$ days, we simulated a situation in which they would have eaten $100 \%$ of each meal. A simulation of the corresponding energy and protein intakes was then carried out. The aim of this simulation was to determine if served diets would allow patients to reach estimated energy and protein targets in the case of full ingestion.

Finally, the second outcome of the study was the functional status of long stayers at hospital discharge. Unfortunately, no validated tool was routinely implemented to assess that outcome. Thus, executive autonomy was recorded. Data have been extracted from the nursing chart, in which autonomy for basic activities was described informally by nurses daily. Patients could be noted as autonomous or not for each of the 3 activities: feeding, bathing, and mobility. Patients were then considered completely autonomous when they were able to mobilize and eat alone and manage their own hygiene.

As it was a pragmatic audit, no sample size was calculated. Statistical analysis was performed by using Graphpad Prism (version 6.0 for Mac OSX, Graphpad Inc, San Diego, CA, USA) and Stata (version 11.2, StataCorp, College Station, TX, USA). Normality was assessed by using the Shapiro-Wilk test. Results are expressed as medians with interquartile range for quantitative variables or as count and percentages for qualitative variables. Comparisons between groups were made by using a $\chi^{2}$ test for categorical variables and by using the Mann-Whitney or Kruskal-Wallis tests for continuous variables. A $P$-value $<.05$ was considered statistically significant. 


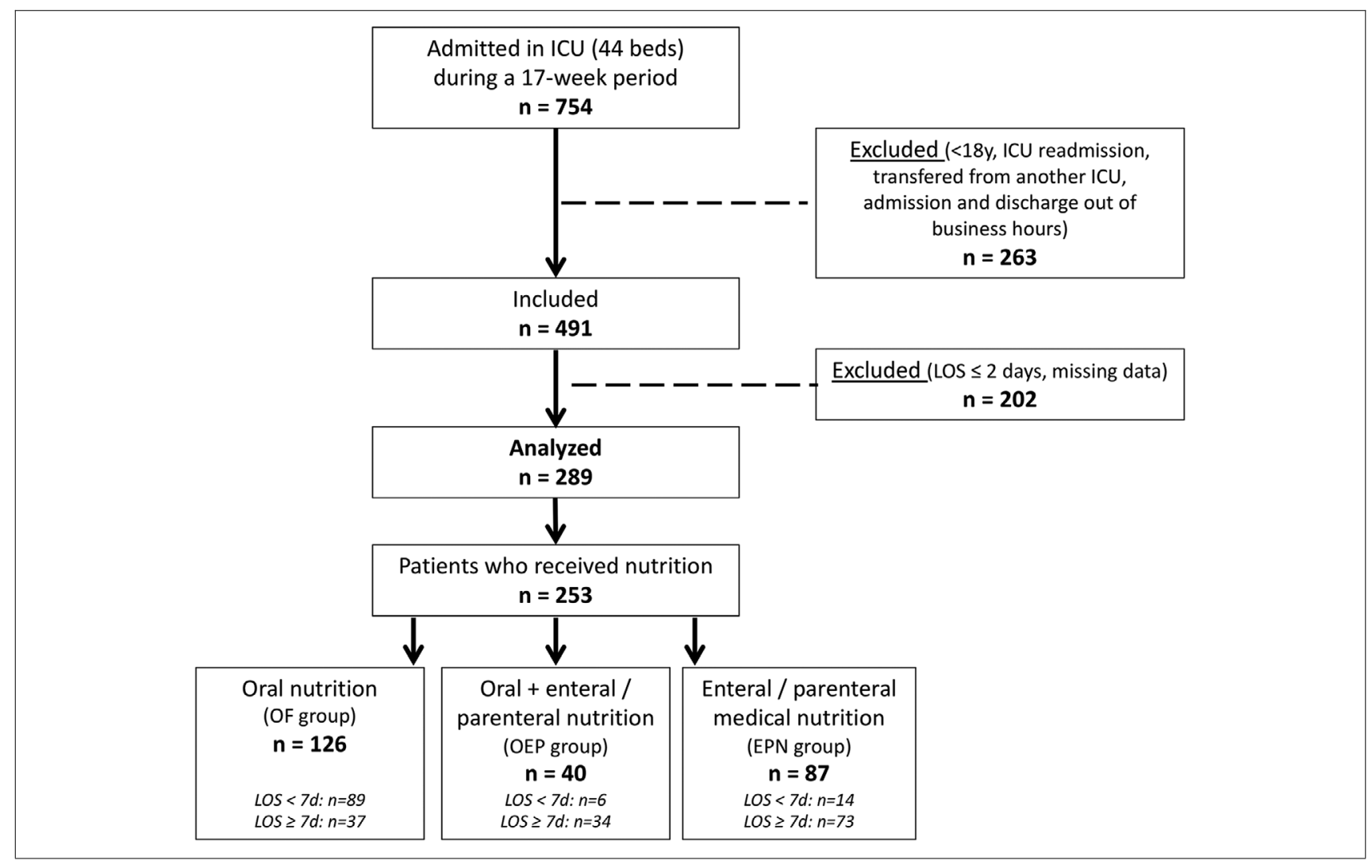

Figure 1. Flow chart of patients recruited and analyzed in the three groups. ICU, intensive care unit; LOS, length of stay.

\section{Results}

Of the 754 patients admitted during the 17 nonconsecutive weeks, between November 2016 and July 2017, data from 289 patients were collected (Figure 1). Descriptive characteristics of the included patients are detailed in Table 2. Median NUTRIC score was 3 (2-5), with $35 \%$ of the patients (102 of 289) having a NUTRIC score $\geq 5$. Weight measured within 48 hours of ICU discharge was available in 100 patients $(34.6 \%)$. In these patients, weight at discharge was similar to the admission weight, as shown by a variation of $-0.3 \%(-4.7 \%$ to $3.3 \%)$. The majority of enterally fed patients had a nasogastric tube, whereas only 8 patients $(2.8 \%)$ had a gastrostomy.

Thirty-six patients (36 of 289 [12\%]) did not receive any nutrition during their ICU stay (LOS 3 [3-4] days) and just received nonnutrition energy from propofol and/or dextrose infusion. For that reason, they were excluded from analysis. The remaining 253 patients were divided into the 3 groups as follows: $126(44 \%)$ in the OF group, $40(14 \%)$ in the OEP group, and $87(30 \%)$ in the EPN group. The groups were comparable for their demographic characteristics, but the severity of disease and ICU and hospital LOS were higher in the OEP and EPN groups than in the OF Group. The proportion of surgical patients was higher in the OF group than in the 2 other groups. (Table 2).

\section{Nutrition Intakes}

The median time before the first nutrition intake was 1 (1-2) day after admission. Daily intakes over the first 7 days are presented in Figure 2. Patients received significantly less energy and protein than the prescribed targets (Figure 2). Overall estimated daily energy and protein targets and actual intakes in nonobese and obese patients are detailed in Table 3. Energy and protein deficits were significantly more severe in the OF group compared with the OEP group and EPN group (Table 4). In the OF group, only 1 patient received ONSs $(0.007 \%)$.

Patients with a NUTRIC score $\geq 5$ had significantly higher energy intakes $(16.6[13.2-20.2] \mathrm{kcal} / \mathrm{kg} / \mathrm{d})$ than patients with a NUTRIC score $<5(14.3$ [8-19.3] kcal $/ \mathrm{kg} / \mathrm{d})$ $(P=.044)$. The same significant observation was made for protein intakes: $0.66(0.53-0.93) \mathrm{g} / \mathrm{kg} / \mathrm{d}$ and 0.56 $(0.3-0.8) \mathrm{g} / \mathrm{kg} / \mathrm{d}$, respectively $(P=.023)$.

Among patients with an ICU LOS $\geq 7$ days $(n=148)$, 4 did not receive any nutrition intakes during their ICU stay. Nearly half of these long stayers belonged to the EPN 
Table 2. Demographics, Clinical Characteristics, and Outcomes of Included Patients.

\begin{tabular}{|c|c|c|c|c|}
\hline Data & $\begin{array}{c}\text { All } \\
\mathrm{N}=289\end{array}$ & $\begin{array}{c}\text { OF group } \\
n=126\end{array}$ & $\begin{array}{l}\text { OEP group } \\
\mathrm{n}=40\end{array}$ & $\begin{array}{c}\text { EPN group } \\
n=87\end{array}$ \\
\hline Age, y & $67(57-75.5)$ & $69(61-75)$ & $63(53-74)$ & $65(54-75$ \\
\hline Male, n (\%) & $171(59)$ & $75(60)$ & $25(62)$ & $48(55)$ \\
\hline Weight, kg & $75(63-86)$ & $77(64.7-88)$ & $77.5(62-89.5)$ & $75(60-84)$ \\
\hline Height, $\mathrm{cm}$ & $170(163-178)$ & $169(163-178)$ & $169.5(165-176)$ & $170(160-180)$ \\
\hline BMI & $25.7(22.7-29.7)$ & $26.2(23.6-30)^{\dagger}$ & $26.7(21.6-30.5)$ & $24.4(20.9-28)$ \\
\hline \multicolumn{5}{|l|}{ Admission category, n (\%) } \\
\hline Medical & $155(54)$ & $50(40)^{*}$ & $31(77)$ & $58(67)$ \\
\hline Surgical & $134(46)$ & $76(60)^{*}$ & $9(23)$ & $29(33)$ \\
\hline \multicolumn{5}{|l|}{ Admission category, n (\%) } \\
\hline Cardiovascular & $142(49)$ & $89(71)$ & $12(30)$ & $23(26)$ \\
\hline Pulmonary & $62(22)$ & $21(17)$ & $15(38)$ & $19(22)$ \\
\hline Neurologic & $32(11)$ & $3(2)$ & $5(12)$ & $21(24)$ \\
\hline Digestive & $26(9)$ & $3(2)$ & $7(18)$ & $10(12)$ \\
\hline Trauma & $8(3)$ & $1(0.8)$ & 0 & $7(8)$ \\
\hline Other & $18(6)$ & $9(7.2)$ & $1(2)$ & $7(8)$ \\
\hline SAPS II & $36(26-49)$ & $31(23-41)^{*}$ & $45(30-52)$ & $46(37-62)$ \\
\hline ICU LOS, d & $7(4-12)$ & $4(3-7)^{*}$ & $11(8-17)$ & $12(7-20)$ \\
\hline Hospital LOS, d & $18(11-34)$ & $14(10-22)^{*}$ & $30(18-41)$ & $32(15-51)$ \\
\hline \multicolumn{5}{|l|}{ Mechanical ventilation } \\
\hline ETT, n $(\%)$ & $164(57)$ & $39(31)^{*}$ & $31(77)$ & $75(86)$ \\
\hline Tracheotomy, n (\%) & $17(6)$ & $0^{*}$ & $2(5)$ & $15(17)$ \\
\hline \multicolumn{5}{|l|}{ Ventilation duration, $\mathrm{d}$} \\
\hline On ETT & $4.5(2-9.7)$ & $1(1-1)^{*}$ & $5(3-9)$ & $9(6-14)$ \\
\hline On tracheotomy & $10(4-19.5)$ & - & $13.5(8-19)$ & $10(4-20)$ \\
\hline $\mathrm{CVVH}, \mathrm{n}(\%)$ & $14(5)$ & $3(2)$ & $3(7)$ & $7(8)$ \\
\hline CVVH duration & $6.5(4-11)$ & $4(4-4)$ & $6(5-12)$ & $9(4-27)$ \\
\hline Intermittent hemodialysis, $\mathrm{n}(\%)$ & $10(3)$ & $3(2)$ & $2(5)$ & $5(6)$ \\
\hline Intermittent hemodialysis duration, $\mathrm{d}$ & $3(1-6)$ & $2(1-3)$ & $3.5(1-6)$ & $3(2-10.5)$ \\
\hline ECMO, n $(\%)$ & $2(0.7)$ & 0 & 0 & $2(2)$ \\
\hline ICU mortality, n (\%) & $34(11.5)$ & $1(0.8)^{*}$ & $2(5)$ & $26(30)$ \\
\hline Hospital mortality, n (\%) & $20(8)$ & $7(5.6)$ & $2(5.3)$ & $8(13)$ \\
\hline
\end{tabular}

BMI was calculated as weight in kilograms divided by height in meters squared.

BMI, body mass index; CVVH, continuous venovenous hemofiltration; ECMO, extracorporeal membrane oxygenation; ETT, endotracheal tube; ICU, intensive care unit; LOS, length of stay; SAPS II, Simplified Acute Physiology Score.

* Significant statistical difference between OF group and OEP group and between OF group and EPN group $(P<.0001)$.

${ }^{\dagger}$ Significant statistical difference between OF group and EPN group $(P=.029)$.

group (Table 5). Patients in the OF group tended to have a higher cumulative energy and protein deficit during their ICU stay (Table 5). In the OF group, the proportion of ICU stay during which energy or protein intakes were $<80 \%$ of estimated targets was significantly higher compared with other groups $(P<.0001)$. However, some patients were overfed, especially in the EPN group, as suggested by energy and even protein intakes exceeding targets (Table 5).

For OF patients with $\mathrm{LOS} \geq 7$ days, a simulated situation of $100 \%$ intake at each authorized meal was performed. In these conditions, their energy and protein intakes during the ICU stay would have reached, respectively, $112 \%$ $(68 \%-131 \%)$ and $67 \%(35 \%-90 \%)$ of the total estimated targets.

\section{Functional Outcome}

A total of 110 patients with an ICU LOS $\geq 7$ days were discharged alive from the hospital, and functional status was available for 82 of them. The proportion of completely autonomous patients in the OF group was not significantly different from the 2 other groups: $26 \%$ (6 of 23), 21\% (5 of $24)$, and $17 \%$ (6 of 35$)$, respectively, $(P=.713)$. Yet, OF patients had a significantly lower SAPS II score (33 [2739]) than the OEP and EPN groups (48.5 [29.3-57.5] and 41 [33-55], respectively, [ $P=.004])$. These OF patients also had a significantly shorter ICU LOS compared with other groups $(P<.0001): 8$ (7-9.8) days vs $15(8.7-19.2)$ days and 15 (12-24.7) days, respectively, for the OEP and EPN groups. 


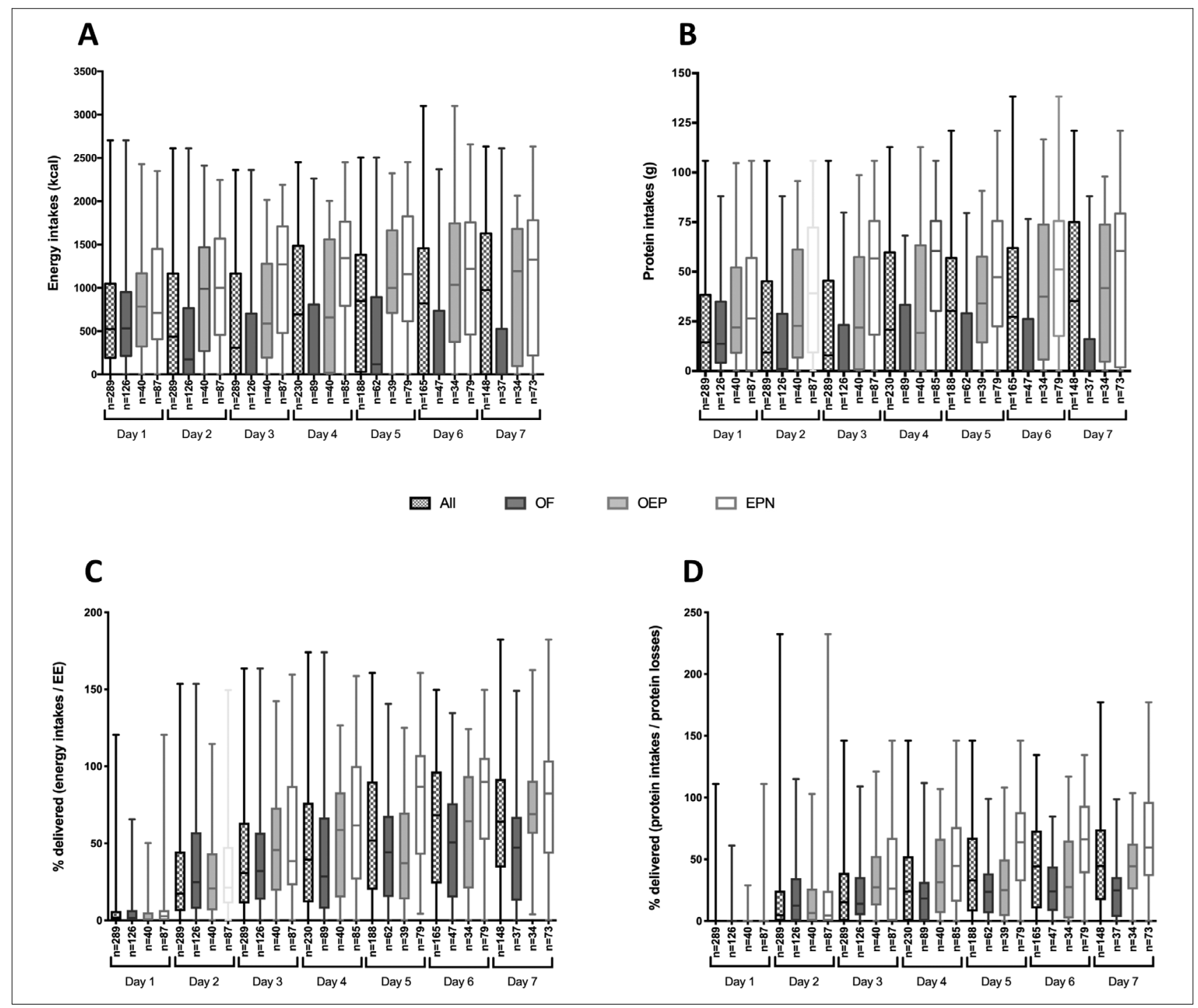

Figure 2. Daily energy (A) or protein (B) intakes and daily percentage of delivered energy (C) or protein (D) during the first 7 days, in the whole cohort and in the 3 groups. EPN, enteral/parenteral nutrition; OEP, oral + enteral/parenteral; OF, orally fed.

Table 3. Nutrition Data in Obese and Nonobese Patients.

\begin{tabular}{lcc}
\hline Data & $\begin{array}{c}\text { Nonobese } \\
\text { patients }(\mathrm{n}=196)\end{array}$ & $\begin{array}{c}\text { Obese patients } \\
(\mathrm{n}=57)\end{array}$ \\
\hline Estimated daily energy target, kcal/d & $1750(1504-1950)$ & $\begin{array}{c}1559 \\
(1447-1734)\end{array}$ \\
Estimated daily protein target, g/d & $84(73.2-93.7)$ & $151.1(141.1-$ \\
$162.2)$ & 9601 \\
Daily energy intakes, $\mathrm{kcal} / \mathrm{d}$ & $1029(549.4-1314)$ & $(576.4-1433)$ \\
Daily protein intakes, $\mathrm{g} / \mathrm{d}$ & $36.93(18.1-54.9)$ & $(18.4-61.3)$ \\
Daily energy intakes, $\mathrm{kcal} / \mathrm{kg} / \mathrm{d}$ & & $12.8(7.8-17.5)$ \\
Daily protein intakes, $\mathrm{g} / \mathrm{kg} / \mathrm{d}$ & $14.9(7.9-19.7)$ & $0.47(0.24-0.7)$ \\
\hline
\end{tabular}


Table 4. Nutrition Data in the 3 Diet Groups of the Entire Studied Population.

\begin{tabular}{|c|c|c|c|c|}
\hline Data & $\begin{array}{l}\text { OF group } \\
(\mathrm{n}=126)\end{array}$ & $\begin{array}{l}\text { OEP group } \\
(\mathrm{n}=40)\end{array}$ & $\begin{array}{l}\text { EPN group } \\
(n=87)\end{array}$ & $P$-value \\
\hline NUTRIC score & $2(2-4)^{\mathrm{a}}$ & $4(2-6)$ & $5(3-7)$ & $<.0001$ \\
\hline Daily energy intakes, $\mathrm{kcal} / \mathrm{kg} / \mathrm{d}$ & $9.7(5.8-16.2)^{\mathrm{a}}$ & $\begin{array}{c}15.1 \\
(11.8-17.7)\end{array}$ & $\begin{array}{c}17.6(13.5- \\
22.1)\end{array}$ & $<.0001$ \\
\hline Daily protein intakes, $\mathrm{g} / \mathrm{kg} / \mathrm{d}$ & $\begin{array}{c}0.35 \\
(0.17-0.57)^{\mathrm{a}}\end{array}$ & $\begin{array}{c}0.57 \\
(0.42-0.71)^{\mathrm{b}}\end{array}$ & $\begin{array}{c}0.81(0.54- \\
1.04)\end{array}$ & $<.0001$ \\
\hline Difference between actual intakes and estimated expenditure, $\%$ & $40(24-67)^{\mathrm{a}}$ & $63(50-77)$ & $72(54-92)$ & $<.0001$ \\
\hline Difference between protein intakes and estimated losses, $\%$ & $24(12-41)^{\mathrm{a}}$ & $44(26-58)^{b}$ & $56(41-83)$ & $<.0001$ \\
\hline
\end{tabular}

Nutrition Risk in Critically Ill (NUTRIC) score.

${ }^{a}$ Significant difference between OF group and OEP group and between OF group and EPN group.

${ }^{\mathrm{b}}$ Significant difference between OEP group and EPN Group.

Table 5. Nutrition Data in the 3 Groups of Patients With ICU LOS $\geq 7$ Days.

\begin{tabular}{|c|c|c|c|c|}
\hline Data & $\begin{array}{l}\text { OF group } \\
(\mathrm{n}=37)\end{array}$ & $\begin{array}{l}\text { OEP group } \\
(\mathrm{n}=34)\end{array}$ & $\begin{array}{l}\text { EPN group } \\
\quad(n=73)\end{array}$ & $P$-value \\
\hline Cumulated difference between intake and target, kcal & $\begin{array}{c}6096 \\
(3696-7957)\end{array}$ & $\begin{array}{c}5875 \\
(3768-8620)\end{array}$ & $\begin{array}{c}4380 \\
(920-8864)\end{array}$ & .375 \\
\hline Cumulated difference between proteins intake and target, $g$ & $487(316-627)$ & $\begin{array}{c}545 \\
(276-1016)^{b}\end{array}$ & $360(165-646)$ & .04 \\
\hline Proportion of ICU stay with energy intakes $<80 \%$ of target, $\%$ & $100(60.6-100)^{\mathrm{a}}$ & $\begin{array}{c}64.8 \\
(47.5-83.3)\end{array}$ & $\begin{array}{c}41.9 \\
(28.3-67.3)\end{array}$ & $<.0001$ \\
\hline Proportion of ICU stay with protein intakes $<80 \%$ of target, $\%$ & $100(100-100)^{\mathrm{a}}$ & $93.1(69.8-100)$ & $62.5(33.8-100)$ & $<.0001$ \\
\hline Proportion of ICU stay with energy intakes $>100 \%$ of target, $\%$ & $0(0-7.5)^{\mathrm{a}}$ & $16.7(0-29.8)$ & $30.4(0-60)$ & $<.0001$ \\
\hline Proportion of ICU stay with protein intakes $>100 \%$ of target, $\%$ & $0(0-0)^{\mathrm{a}}$ & $0(0-15.4)$ & $8.5(0-42.7)$ & $<.0001$ \\
\hline
\end{tabular}

ICU, intensive care unit; LOS, length of stay.

${ }^{a}$ Significant difference between OF group and OEP group and between OF group and EPN group.

${ }^{\mathrm{b}}$ Significant difference between OEP group and EPN Group.

\section{Discussion}

The main finding of this study was the lower nutrition intakes by oral feeding compared with other exclusive or combined medical nutrition. Relative to the prescribed amounts, the deficit was larger for proteins than for energy. Surprisingly, supplementation with industrial ONSs or with protein supplements was extremely rare. When looking at functional autonomy, the present results were challenging. Unexpectedly, despite a lower severity of disease and a shorter LOS, the functional status of the OF patients was not better than in the other groups. The hypothetical link between higher energy and/or protein deficit in the OF group and the absence of a difference in functional status should be further investigated.

The observed population was representative of the typical ICU population of developed countries and was similar to the "nutritionDay" ICU population, at least in terms of age, BMI, and severity of illness. ${ }^{11}$ Although similar observations had already been reported in a previously published study, ${ }^{22}$ underfeeding and insufficient awareness of OF patients' conditions can potentially be a reality in other ICUs. This highlights the need for a better translation of the recommendations into practices, in particular for $\mathrm{OF}$ patients. ${ }^{23-25}$

Oral feeding is a real challenge in ICUs. ${ }^{12}$ The barriers to food intakes are numerous ${ }^{26,27}$ and related to illness effects (such as anorexia, ${ }^{28,29}$ changes in the perception of food taste, ${ }^{30}$ and disturbed gastrointestinal function ${ }^{31}$ ), eating difficulties, and organizational processes. ${ }^{32}$ If regular and disease-specific diets are generally prepared to cover $100 \%$ of the daily energy requirements (as demonstrated by the present simulation), they provide on average only $0.8 \mathrm{~g} / \mathrm{kg} / \mathrm{d}$ protein. Such a protein supply is supposed to meet the needs of healthy and hospitalized patients ${ }^{33}$ but seems to be insufficient for critically ill patients. Indeed, according to the recent European Society of Parenteral and Enteral Nutrition, in critically ill patients, protein intake should be gradually increased to reach $1.3 \mathrm{~g} / \mathrm{kg} / \mathrm{d}$ protein. ${ }^{5}$ Such amount is even slightly higher than the one targeted in the present study. These pitfalls emphasize the need for a close follow-up of OF patients. Energy and protein intakes should be monitored on a daily basis and supplemented, as required. Several options are available to ensure adequate intakes, even if not fully supported 
by strong evidence. Previous studies in ICU brain-injured patients or survivors demonstrated that oral supplements (enriched diets, ONSs, or protein supplements) can at least partially fill the nutrition deficits observed with exclusive oral nutrition. ${ }^{7,10}$ In the case of insufficient oral feeding, supplemental enteral nutrition should be considered. Computerized recording of actual nutrition intakes on a daily basis, regular weight measurement, and collaboration with specialized dieticians could be additional strategies that may help achieve adequate nutrition. ${ }^{34} \mathrm{OF}$ patients could benefit from dieticians' advice regularly, as they are able to tailor diets and supplements based on actual intakes and needs, clinical situation, and patient food preferences. There is an urgent need to educate both nursing and medical teams on the risk of insufficient nutrition supply in OF patients. Such strategies could also be helpful to avoid overfeeding. This potential issue has been observed in a portion of patients in the present audit, as in other previous studies. ${ }^{10,35}$ The reason why this happens is still unclear, but the impact on respiratory or metabolic outcomes would need further investigations. ${ }^{35}$

Nutrition is not just a question of quantity but also of timing. ${ }^{36}$ The challenge is to adapt nutrition daily on the basis of clinical and inflammation status, organ dysfunction, level of sedation, pain, weaning from respiratory support, or physical activity. These parameters will vary considerably during the ICU stay. Therefore, the nutrition prescription should not be static but rather should be adapted daily depending on the patient's clinical condition. To date, there are no biological markers to guide nutrition prescriptions, and patients may, therefore, inadvertently be underfed or overfed during their ICU stay. ${ }^{36}$ In this study, patients' nutrition requirements were considered to be constant throughout their ICU stay, regardless of the variation of inflammation status, the occurrence of shock, organ failure, or variation of physical activity, for example. In noncritically ill hospitalized patients, the implementation of an individualized strategy including successive steps of oral, enteral, and parenteral nutrition has been associated with a decrease in mortality. ${ }^{37}$

The strength of this study is that a pragmatic real-life audit was performed in a large population. Specific attention was paid to oral intakes that were recorded daily until discharge. However, some limitations need to be acknowledged. First, there was no assessment of the nutrition status at admission in ICU. The optimal approach for nutrition assessment in ICUs is still uncertain. The NUTRIC score, as used in the present study, reflects the severity of disease rather than the nutrition status. ${ }^{38,39}$ Nevertheless, it is not so obvious that outcomes may be modified by the nutrition strategy according to the initial nutrition status. ${ }^{39,40}$ Second, the recording of oral intakes by the nursing team may have been imprecise (because of the method used) or incorrect. Moreover, food brought by families was not recorded for
OF patients. This may have led to an underestimation of energy intakes but probably not of protein intakes because families tend to bring sugar-based products (sweets), and rarely protein-rich foods, to their relatives. This is typical habit in Belgian hospitals and has been well documented during the "nutritionDay" audit (unpublished data). Third, indirect calorimetry and nitrogen balance were not routinely measured in the studied population. Additionally, energy from citrate used for regional anticoagulation in patients on continuous venovenous hemofiltration were not considered. At worst, energy from citrate represents 100 $200 \mathrm{kcal} / \mathrm{d} \cdot{ }^{41,42}$ In these patients, energy intakes may have been slightly underestimated, but this should not affect our conclusions regarding energy intakes and does not affect our findings on protein intakes. Fourth, a formal assessment of performances in activities of daily living, muscle strength, and muscle function were not performed, as it was not part of the local clinical practices. The quantification of muscle strength in ICU patients involves methodological uncertainties, among which there is the choice, relevant from a clinical point of view, of the muscle group to be tested but also the methods of strength assessment. In a recent study, a dynamometry protocol (aiming at overcoming the pitfalls of measurement standardization) could be implemented at the bedside and allow early monitoring of muscle strength. ${ }^{43}$ Fifth, there was no systematic screening for refeeding syndrome. Occurrence of such syndrome may have impacted energy intake during the first days of refeeding. Sixth, food behavior may have been disrupted by some drugs. This component of oral feeding was not investigated in $\mathrm{OF}$ patients. It is obviously an interesting factor that should be taken into account when trying to orally feed critically ill patients. Seventh, we included in the OEP group the patients who received either concomitant or successive oral and enteral or parenteral nutrition. As the study was focused on exclusively OF patients, the heterogeneity of the trajectories of OEP patients was not taken into account. Finally, in this pragmatic study, the data required for a relevant adjustment of the analysis of outcomes were not available.

In conclusion, the present audit allowed the quantification of nutrition intakes in OF patients in ICUs. It was observed that nutrition intakes were lower than prescribed targets by exclusive oral feeding, with a larger deficit for protein than for energy intakes. Such results should help persuade intensivists, nurses, and dieticians to view oral nutrition as a key component of critical care and not only as a comfort care.

\section{Acknowledgments}

We want to thank Pr Pierre Damas (PhD), Pr Bernard Lambermont (PhD), Pr Patrizio Lancelotti (PhD), Dr Xavier Mathy (MD), and Thomas Lejeune (RD) for their valuable contribution in data collection. 


\section{Statement of Authorship}

M. Fadeur, A.-M. Verbrugge, and A.-F. Rousseau contributed to the conception and design of the research; L. Rougier and A.-F. Rousseau contributed to the acquisition and analysis of the data; J.-C. Preiser, M. Fadeur, N. Paquot, D. Ledoux, and A.-F. Rousseau contributed to the interpretation of the data; and J.-C. Preiser and A.-F. Rousseau drafted the manuscript. M. Fadeur, N. Paquot, D. Ledoux, and B. Misset critically revised the manuscript. All authors agree to be fully accountable for ensuring the integrity and accuracy of the work and read and approved the final manuscript.

\section{References}

1. Casaer MP, Van den Berghe G. Nutrition in the acute phase of critical illness. $N$ Engl J Med. 2014;370(13):1227-1236.

2. Dvir D, Cohen J, Singer P. Computerized energy balance and complications in critically ill patients: an observational study. Clin Nutr. 2006;25(1):37-44.

3. Villet S, Chiolero RL, Bollmann MD, et al. Negative impact of hypocaloric feeding and energy balance on clinical outcome in ICU patients. Clin Nutr. 2005;24(4):502-509.

4. McClave SA, Taylor BE, Martindale RG, et al. Guidelines for the Provision and Assessment of Nutrition Support Therapy in the Adult Critically Ill Patient: Society of Critical Care Medicine (SCCM) and American Society for Parenteral and Enteral Nutrition (A.S.P.E.N.). JPEN J Parenter Enteral Nutr. 2016;40(2):159-211.

5. Singer $P$, Blaser AR, Berger MM, et al. ESPEN guideline on clinical nutrition in the intensive care unit. Clin Nutr. 2019;38(1): 48-79.

6. Peterson SJ, Tsai AA, Scala CM, Sowa DC, Sheean PM, Braunschweig $\mathrm{CL}$. Adequacy of oral intake in critically ill patients 1 week after extubation. $J$ Am Diet Assoc. 2010;110(3):427-433.

7. Chapple LS, Deane AM, Heyland DK, et al. Energy and protein deficits throughout hospitalization in patients admitted with a traumatic brain injury. Clin Nutr. 2016;35(6):1315-1322.

8. Macht M, White SD, Moss M. Swallowing dysfunction after critical illness. Chest. 2014;146(6):1681-1689.

9. Brodsky MB, Levy MJ, Jedlanek E, et al. Laryngeal injury and upper airway symptoms after oral endotracheal intubation with mechanical ventilation during critical care: a systematic review. Crit Care Med. 2018;46(12):2010-2017.

10. Ridley EJ, Parke RL, Davies AR, et al. What happens to nutrition intake in the post-intensive care unit hospitalization period? An observational cohort study in critically ill adults. JPEN J Parenter Enteral Nutr. 2019;43(1):88-95.

11. Bendavid I, Singer P, Theilla M, et al. NutritionDay ICU: a 7 year worldwide prevalence study of nutrition practice in intensive care. Clin Nutr. 2017;36(4):1122-1129.

12. Massanet PL, Petit L, Louart B, Corne P, Richard C, Preiser JC. Nutrition rehabilitation in the intensive care unit. JPEN $J$ Parenter Enteral Nutr. 2015;39(4):391-400.

13. Vincent JL, Preiser JC. When should we add parenteral to enteral nutrition? Lancet. 2013;381(9864):354-355.

14. Leder SB, Suiter DM, Warner HL, Kaplan LJ. Initiating safe oral feeding in critically ill intensive care and step-down unit patients based on passing a 3-ounce (90 milliliters) water swallow challenge. J Trauma. 2011;70(5):1203-1207

15. Lefrant JY, Hurel D, Cano NJ, Ichai C, Preiser JC, Tamion F. [Guidelines for nutrition support in critically ill patient]. Ann Fr Anesth Reanim. 2014;33(3):202-218.
16. Deschamps V, Astier X, Ferry M, Rainfray M, Emeriau JP, BarbergerGateau P. Nutritional status of healthy elderly persons living in Dordogne, France, and relation with mortality and cognitive or functional decline. Eur J Clin Nutr. 2002;56(4):305-312.

17. Wiesen P, Van Overmeire L, Delanaye P, Dubois B, Preiser JC. Nutrition disorders during acute renal failure and renal replacement therapy. JPEN J Parenter Enteral Nutr. 2011;35(2):217-222.

18. Ostermann M, Macedo E, Oudemans-van Straaten H. How to feed a patient with acute kidney injury. Intensive Care Med. 2019;45(7):10061008.

19. Heyland DK, Stephens KE, Day AG, McClave SA. The success of enteral nutrition and ICU-acquired infections: a multicenter observational study. Clin Nutr. 2011;30(2):148-155.

20. de Vries MC, Koekkoek WK, Opdam MH, van Blokland D, van Zanten AR. Nutritional assessment of critically ill patients: validation of the modified NUTRIC score. Eur J Clin Nutr. 2018;72(3): 428-435.

21. Berrut G, Favreau AM, Dizo E, et al. Estimation of calorie and protein intake in aged patients: validation of a method based on meal portions consumed. J Gerontol A Biol Sci Med Sci. 2002;57(1):M52-56.

22. Soguel L, Revelly JP, Schaller MD, Longchamp C, Berger MM. Energy deficit and length of hospital stay can be reduced by a twostep quality improvement of nutrition therapy: the intensive care unit dietitian can make the difference. Crit Care Med. 2012;40(2):412-419.

23. Reintam Blaser A, Deane AM, Starkopf J. Translating the European Society for Clinical Nutrition and Metabolism 2019 guidelines into practice. Curr Opin Crit Care. 2019;25(4):314-321.

24. Peterson SJ, Sheean PM, Braunschweig CL. Orally fed patients are at high risk of calorie and protein deficit in the ICU. Curr Opin Clin Nutr Metab Care. 2011;14(2):182-185.

25. Merriweather J, Smith P, Walsh T. Nutritional rehabilitation after ICU - does it happen: a qualitative interview and observational study. J Clin Nurs. 2014;23(5-6):654-662.

26. Keller H, Allard J, Vesnaver E, et al. Barriers to food intake in acute care hospitals: a report of the Canadian Malnutrition Task Force. J Hum Nutr Diet. 2015;28(6):546-557.

27. Moisey L. A Comprehensive Assessment of Nutritional Status and Factors Impacting Nutrition Recovery in Hospitalized, Critically Ill Patients Following Liberation from Mechanical Ventilation. Doctorate thesis. University of Waterloo, Ontario, Canada; 2017.

28. Merriweather JL, Griffith DM, Walsh TS. Appetite during the recovery phase of critical illness: a cohort study. Eur J Clin Nutr. 2018;72(7):986-992.

29. Nematy M, O'Flynn JE, Wandrag L, et al. Changes in appetite related gut hormones in intensive care unit patients: a pilot cohort study. Crit Care. 2006;10(1):R10.

30. Chapple LS, Weinel LM, Abdelhamid YA, et al. Observed appetite and nutrient intake three months after ICU discharge. Clin Nutr. 2019;38(3):1215-1220.

31. Ritz MA, Fraser R, Tam W, Dent J. Impacts and patterns of disturbed gastrointestinal function in critically ill patients. Am J Gastroenterol. 2000;95(11):3044-3052.

32. Naithani S, Whelan K, Thomas J, Gulliford MC, Morgan M. Hospital inpatients' experiences of access to food: a qualitative interview and observational study. Health Expect. 2008;11(3):294-303.

33. Recommandations Nutritionnelles pour la Belgique [Dietary Guidelines for Belgium]. https://www.health.belgium.be/sites/default/ files/uploads/fields/fpshealth_theme_file/css_9285_avis_rec_nutr.pdf. 2016. Accessed April 21, 2020

34. Berger MM, Revelly JP, Wasserfallen JB, et al. Impact of a computerized information system on quality of nutritional support in the ICU. Nutrition. 2006;22(3):221-229. 
35. Chapple LS, Weinel L, Ridley EJ, Jones D, Chapman MJ, Peake SL. Clinical sequelae from overfeeding in enterally fed critically ill adults: where is the evidence? JPEN J Parenter Enteral Nutr. Published online November 17, 2019. doi:10.1002/jpen.1740.

36. Berger MM, Pichard C. Feeding should be individualized in the critically ill patients. Curr Opin Crit Care. 2019;25(4):307-313.

37. Schuetz P, Fehr R, Baechli V, et al. Individualised nutritional support in medical inpatients at nutritional risk: a randomised clinical trial. Lancet. 2019;393(10188):2312-2321.

38. Lee ZY, Heyland DK. Determination of nutrition risk and status in critically ill patients: what are our considerations? Nutr Clin Pract. 2019;34(1):96-111.

39. Arabi YM, Casaer MP, Chapman M, et al. The intensive care medicine research agenda in nutrition and metabolism. Intensive Care Med. 2017:43(9):1239-1256.
40. Alberda C, Gramlich L, Jones N, et al. The relationship between nutritional intake and clinical outcomes in critically ill patients: results of an international multicenter observational study. Intensive Care Med. 2009;35(10):1728-1737.

41. Fiaccadori E, Regolisti G, Maggiore U. Specialized nutritional support interventions in critically ill patients on renal replacement therapy. Curr Opin Clin Nutr Metab Care. 2013;16(2):217224.

42. Bousie E, van Blokland D, Lammers HJ, van Zanten AR. Relevance of non-nutritional calories in mechanically ventilated critically ill patients. Eur J Clin Nutr. 2016;70(12):1443-1450.

43. Rousseau AF, Kellens I, Freycenon G, et al. Highly standardized quadriceps dynamometry of critically ill adults at bedside: a step towards individualized rehabilitation. Acta Anaesthesiol Belg. 2018;69(3):159-164 